\title{
Avaliação do poder calorífico da biomassa algal obtida por coagulação-floculação
}

\section{Evaluation of the calorific value of algal biomass obtained by coagulation-flocculation}

Data de entrada: 19/08/2018

Data de aprovação: $25 / 08 / 2018$

Renan Barroso Soares ${ }^{1 \%}$ | Ricardo Franci Gonçalves ${ }^{1}$ | Marcio Ferreira Martins ${ }^{2}$ | Zudivan Peterli

DOI: https://doi.org/10.36659/dae.2020.030

\section{ORCID ID}

Soares RB (iD https://orcid.org/0000-0002-9508-0036

Gonçalves RF (D) https://orcid.org/0000-0002-2048-9451
Martins MF (D) https://orcid.org/0000-0002-3023-222X

Peterli Z (DD https://orcid.org/0000-0002-8929-0125

\section{Resumo}

A produção de microalgas nas Estações de Tratamento de Esgoto (ETE) está deixando de ser vista como um problema e passando a ser vislumbrada como matéria-prima para a obtenção de biocombustível. A biomassa algal apresenta poder calorífico superior (PCS) similar ao da madeira e pode ser usado em processos termoquímicos para a geração de energia. Contudo, essa análise requer mais atenção, uma vez que a literatura normalmente apresenta o PCS para espécies puras de microalgas e sem a presença de coagulantes. Este trabalho analisou a influência de diferentes coagulantes comerciais no PCS da biomassa algal, obtida em lagoas de alta taxa com efluente de reator UASB. Além dos coagulantes inorgânicos tradicionais, polímeros catiônicos também foram avaliados. O coagulante polímero catiônico polydadmac teve o melhor custo-benefício e o PCS deste lodo foi de $21,19 \mathrm{MJ} / \mathrm{Kg}$.

Palavras-chave: Microalgas. Esgoto. Coagulação. Floculação. Poder calorífico. Energia.

\section{Abstract}

The production of microalgae in Wastewater Treatment Plants (WWTP) is no longer seen as a problem and is now seen as a raw material for obtaining biofuel. The algal biomass presents higher calorific value (HHV) similar to that of wood and can be used in thermochemical processes for the generation of energy. However, this analysis requires more attention, since the literature normally presents HHV for pure species of microalgae and without the presence of coagulants. This work analyzed the influence of different commercial coagulants on HHV of algal biomass, obtained in high-rate lagoons with UASB reactor effluent. In addition to traditional inorganic coagulants, cationic polymers have also been evaluated. The coagulant polymer cation polydadmac had the best cost benefit and the HHV of this sludge was $21.19 \mathrm{MJ} / \mathrm{kg}$.

Keywords: Microalgae. Sewage. Coagulation. Flocculation. Heat value. Energy.

\footnotetext{
${ }^{1}$ Universidade Federal do Espírito Santo - Departamento de engenharia ambiental - Vitória - ES - Brasil.

2 Universidade Federal do Espírito Santo - Departamento de engenharia mecânica - Vitória - ES - Brasil.

${ }^{3}$ Universidade Federal de Itajubá - Núcleo de Excelência em Geração Termelétrica e Distribuída - Itajubá - MG - Brasil.

* Autor correspondente: renanbarroso.offshoreahotmail.com.
} 


\section{INTRODUÇÃO}

O uso de energia é associado ao desenvolvimento econômico-social, e garantir a segurança energética, de maneira sustentável, é um dos maiores esforços da sociedade (RAHEEM et al., 2015). Atualmente, com o ritmo de consumo mundial diário de óleo e de gás, estima-se que as reservas durem 49 e 70 anos, respectivamente (SOREANU et al., 2017). Além da depleção das reservas, o uso extenso de combustíveis fósseis tem contribuído para a emissão de gases do efeito estufa. Esse contexto motiva a busca por novas fontes de energia, mais limpas e renováveis. Dentre as opçõe possíveis, a energia de biomassa é vantajosa, uma vez que atende à necessidade de combustível líquido e gasoso, para integrar a infraestrutura já existente (PATEL et al., 2016), e pode ser ajustada, conforme a necessidade momentânea de consumo (HEIDENREICH e FOSCOLO, 2015). Para suprir toda essa demanda, é improvável que a biomassa de agricultura seja suficiente, e as microalgas são consideradas a alternativa mais promissora (VANDAMME et al., 2013).

A produção de biomassa algal apresenta várias vantagens se comparada à biomassa tradicional de culturas terrestres. A taxa de crescimento pode ser até cem vezes superior à das plantas terrestres, dobrando sua biomassa em menos de um dia (LAM e LEE, 2014). Outras vantagens são a possibilidade de cultivo em áreas inférteis, como desertos e regiões costeiras, em águas salinas, salobras, e águas residuárias. Além disso, o cultivo ainda permite a incorporação de $\mathrm{CO}_{2}$ gerado em processos industriais, adicionando-se um benefício extra (JANKOWSKA et al., 2017). Por tudo isso, as microalgas têm se consolidado como matriz essencial para os biocombustíveis de terceira geração, abrindo uma nova dimensão na indústria de energia renovável (PENG et al., 2017).
Atualmente, a produção de microalgas para a geração de biocombustível não é economicamente viável. O motivo principal é o alto custo de colheita, estimado em $30 \%$ do custo total de produção da biomassa (GERCHMAN et al., 2017), podendo chegar a $60 \%$ do custo total do biocombustível produzido (CASTRILLO et al., 2013). A dificuldade na colheita de microalgas está associada com a diluição da cultura, que se apresenta com baixa concentração de biomassa. 0 processo de floculação tem sido considerado o melhor método para colher microalgas, devido à sua capacidade de processar uma grande quantidade de volume em um custo relativamente baixo. No entanto, a incorporação desses compostos químicos à biomassa pode afetar os processos subsequentes. Cloretos de alumínio, por exemplo, podem inibir as reações de transesterificação e prejudicar a produção de biodiesel (WAN et al., 2015). Sulfato de alumínio e cloreto férrico podem afetar a digestão anaeróbia, prejudicando a geração de biogás (ANTHONY et al., 2013). Para os processos termoquímicos, como incineração, gaseificação e pirólise, a adição de frações inorgânicas na biomassa reduz o seu poder calorífico, e essa alteração não está totalmente compreendida e quantificada na literatura. Normalmente, o poder calorífico de microalgas é descrito para espécies puras e isentas de coagulantes. Contudo, o cultivo de uma única espécie de microalga e a colheita por processos que não envolvam o uso de coagulantes, como centrifugação e filtração, por exemplo, não se inserem no contexto mais provável para a valorização energética de microalgas. No curto prazo, a combinação de tratamento de esgoto com a produção de biocombustível tem sido apontada como o cenário mais plausível para aplicação comercial do cultivo de microalgas (MANARA e ZABANIOTOU, 2012), e isso envolve a obtenção de uma biomassa algal composta por diferentes espécies de microalgas e a presença de coagulantes químicos. 


\section{OBJETIVOS}

Este trabalho tem como objetivo analisar a influência do coagulante no PCS da biomassa algal, obtida em lagoas de alta taxa com efluente de reator UASB. Além dos coagulantes inorgânicos tradicionais, compostos orgânicos também são avaliados. As dosagens utilizadas estão baseadas em ensaios de Jar Test, e uma análise de custos também é abordada.

\section{METODOLOGIA}

\subsection{Cultivo de microalgas}

O cultivo de microalgas foi feito na estação de tratamento piloto de Araçás, localizada no município de Vila Velha, no estado do Espírito Santo. Duas lagoas de alta taxa foram construídas em plástico reforçado com fibra de vidro (PRFV), cada uma com volume útil total $13,7 \mathrm{~m}^{3}$, com dois canais com comprimento de $10,0 \mathrm{~m}$, largura de $2,4 \mathrm{~m}$ e área de 22,8m2 (Fig. 1). As lagoas foram alimentadas com o efluente anaeróbio do tratamento de esgoto no reator UASB, construído em plástico reforçado com fibra de vidro (PRFV), com diâmetro de 1,0m, altura útil de $4,8 \mathrm{~m}$, volume útil total de $3,8 \mathrm{~m}^{3}$ vazão média de operação de $0,14 \mathrm{~L} / \mathrm{s}$. Um sistema de gradeamento, preliminar ao reator UASB, foi usado para remover os sólidos grosseiros do esgoto bruto. $O$ efluente das lagoas foi coletado em uma bombona plástica de 80L, e os ensaios de Jar Test foram feitos logo após a coleta.

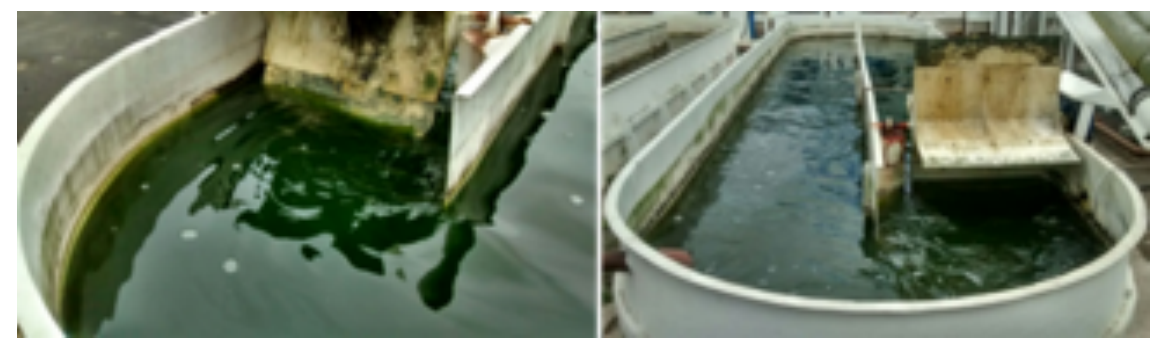

Figura 1. Lagoa de alta taxa para a produção de microalgas

\subsection{Ensaios de Jar Test}

Os ensaios de Jar Test foram feitos em triplicata, na condição de $\mathrm{pH}$ natural da lagoa. O procedimento operacional foi baseado em FERRARI (2004), com velocidade de $105 \mathrm{rpm}$ por $2 \mathrm{~min}$ para o período de mistura e velocidade de 30rpm por 10 min para o período de floculação. $O$ tempo de decantação foi de $30 \mathrm{~min}$. $\mathrm{O}$ pH foi mensurado em pHmêtro digital e a eficiência de separação foi estimada com base na densidade ópitica a $750 \mathrm{~nm}$, confrontando-se os valores inicial e final do meio, coforme reportado por DAS et al. (2016) e dado pela Eq. 1. Em cada jarro do equipamento, um volume de $2 \mathrm{~L}$ da cultura foi adicionado, e as amostragens do sobrenadante foram tomadas no ponto de coleta do jarro, a $1 \mathrm{~L}$ do fundo, após o tempo de decantação. $\mathrm{O}$ pH do sobrenadante também foi mensurado.

Eficiência da colheita $=\frac{O D i-O D f}{O D i} \times 100$

Onde $\mathrm{OD}_{\mathrm{i}}$ é a densidade óptica inicial do meio de cultura e $\mathrm{OD}_{\mathrm{f}}$ é a densidade óptica final do sobrenadante após a decantação.

Todos os materias usados como coagulantes foram obtidos de forma comercial, evitando-se o uso de reagentes laboratorias de alta pureza, para representar um cenário mais real. As dosagens utilizadas se referem ao produto comercial, e não ao teor do componente ativo dentro do produto comercial. Quando necessário, diluições foram 
feitas com água destilada, para ajustar a concentração do coagulante para os ensaios. Foram testados cloreto férrico, sulfato de alumínio ferroso, policloreto de alumínio, polímero catiônico polissintético de óxidos ácidos e derivados nitrogenados e polímero catiônico polydadmac. Além desses, cal hidratada também foi usada como meio de coleta de microalgas, visto que muitas espécies podem ser colhidas, com eficiência superior a 95\%, pelo simples aumento de pH CASTRILLHO et al. 2013; WAN et al., 2015). Além disso, o custo do material é extremamente baixo e a presença de cálcio na biomassa pode ser benéfica para alguns processos termoquímicos, tal como a gaseificação, uma vez que o material pode absorver gases contaminantes, indesejáveis no processo (LÓPEZ-GONZÁLEZ et al., 2014). Para cada ensaio, os coagulantes foram adicionados simultaneamente. $\mathrm{O}$ mesmo foi feito com a amostragem do sobrenadante, para que os tempos de agitação e decantação fossem iguais para todas as concentrações avaliadas em cada jarro.

\subsection{Processo de colheita}

Uma vez determinada a dosagem ótima de cada coagulante nos ensaios de Jar Test, 200L do meio de cultura foram colocados em uma bombona plástica. $O$ coagulante foi adicionado e um agitador mecânico foi acoplado sobre a bombona, mantendo-se agitação por $30 \mathrm{~min}$. 0 material foi deixado em repouso para decantação por $24 \mathrm{~h}$ e a água foi drenada por torneiras acopladas na bombona. Ao final, a biomassa algal obtida no fundo da bombona foi adensada em tecido. 0 processo de colheita da biomassa algal com o uso de coagulantes é mostrado na Fig. 2.

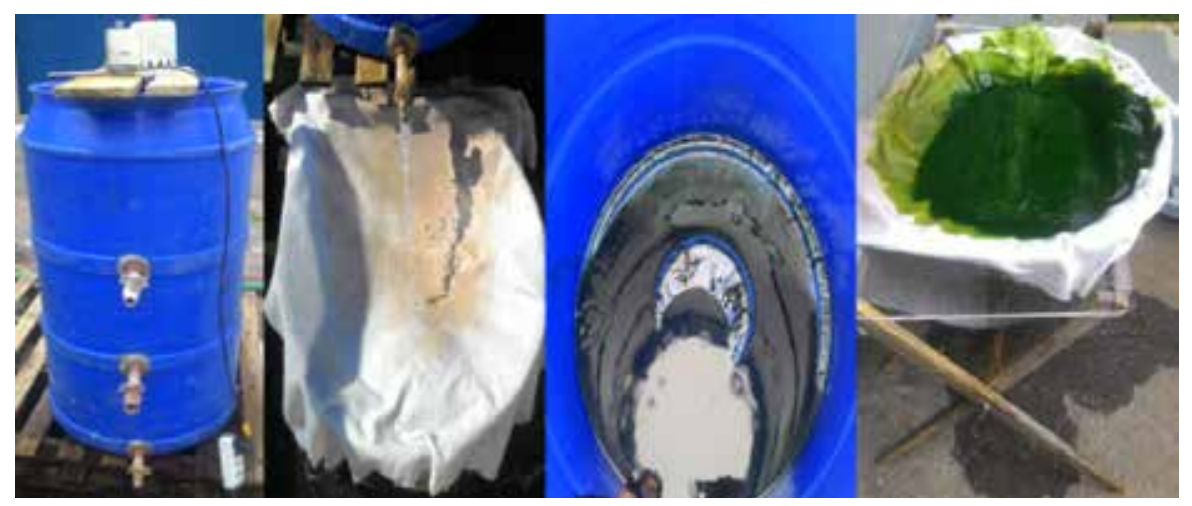

Figura 2. Processo de colheita da biomassa algal com o uso de coagulantes

Para avaliar a biomassa algal sem a presença de coagulates, um sistema de filtração a vácuo foi montado com kitassato e funil de buncher. 0 reboco da biomassa algal, aderido ao papel de filtro, foi removido delicadamente com espátula e colocado em um cadinho, para posterior secagem. Esse método de colheita é apresentado na Fig. 3. 


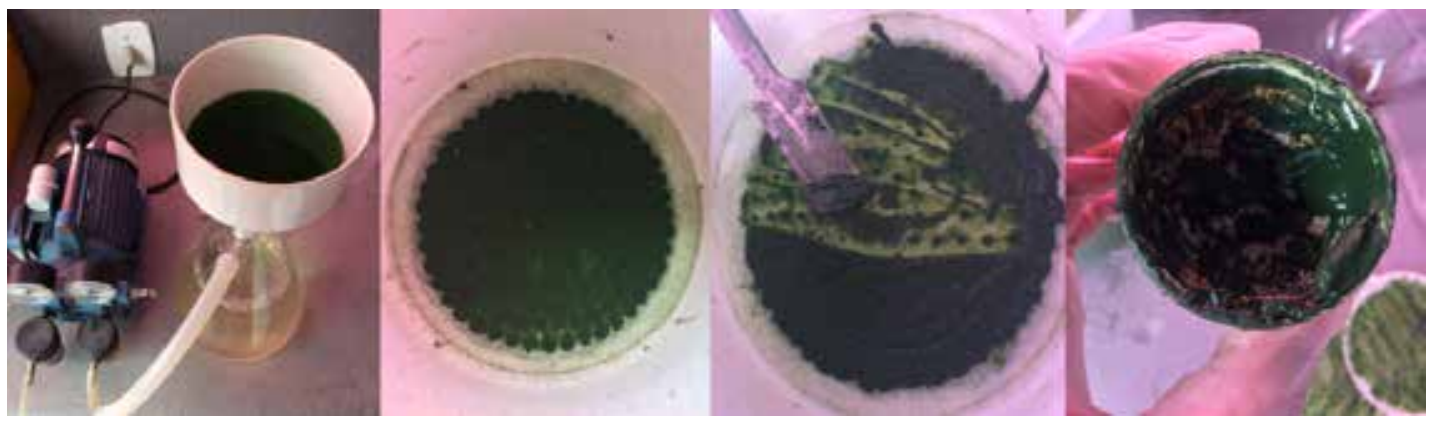

Figura 3. Processo de colheita da biomassa algal sem o uso de coagulantes

\subsection{Preparação das amostras e determinação do poder calorífico}

As amostras de lodo foram colocadas em bandejas de alumínios e deixadas em uma estufa de pré-secagem a $60^{\circ} \mathrm{C}$, em ambiente externo, para remover o excesso de umidade e os odores. Depois, a higienização do lodo e a remoção da umidade foram completadas em uma estufa convencional a $103^{\circ} \mathrm{C}$, por no mínimo $12 \mathrm{~h}$. Cada amostra foi então triturada em moinho de argola, até a obtenção de um pó muito fino, e submetida aos ensaios de poder calorífico. $A$ análise do poder calorífico superior foi feita em triplicata, no calorímetro de modelo $\mathrm{C} 2000$, do fabricante IKA- Werke. Foi realizada a pesagem da amostra em microbalança de precisão, para obter uma massa próxima de $0,5 \mathrm{~g}$. A amostra foi acondicionada, em pó, no cadinho da bomba calorimétrica, juntamente com o fio de algodão empregado para realizar a ignição da reação de combustão. A bomba foi fechada e carregada até 30bar, de forma automática, pelo próprio equipamento de análise, com uma carga de oxigênio puro. O resíduo gerado após a combustão, composto pelas cinzas, foi coletado para análise posterior. Os aspectos da biomassa algal, antes e após a etapa de moagem, assim como os das cinzas obtidas após a determinação do PCS, foram registrados.

\section{RESULTADOS E DISCUSSÃO}

A Fig. 4 apresenta a eficiência obtida na colheita para os diferentes coagulantes testados, em diferentes dosagens, enquanto a Tabela 1 traz os resultados de $\mathrm{pH}$, dosagem recomendada, eficiência e custo. A dosagem recomendada foi definida para uma eficiência mínima de colheita de $85 \%$. Esse valor foi definido com base na Fig. 4, uma vez que representa uma eficiência média próxima da ideal, para todos os coagulantes testados. Nota-se que alguns produtos, especialmente o polímero catiônico polydadmac, apresentaram um ponto de máximo em sua curva de eficiência, com declínio acentuado para concentrações mais altas. Assim, recomenda-se um estudo exaustivo de Jar Test para esses coagulantes, antes de sua aplicação, para que a eficiência na colheita seja a maior possível e não ocorram resultados indesejados. Apenas a cal hidratada e o polímero catiônico polydadmac não atingiram uma eficiência experimental de $85 \%$, ficando ligeiramente abaixo. 


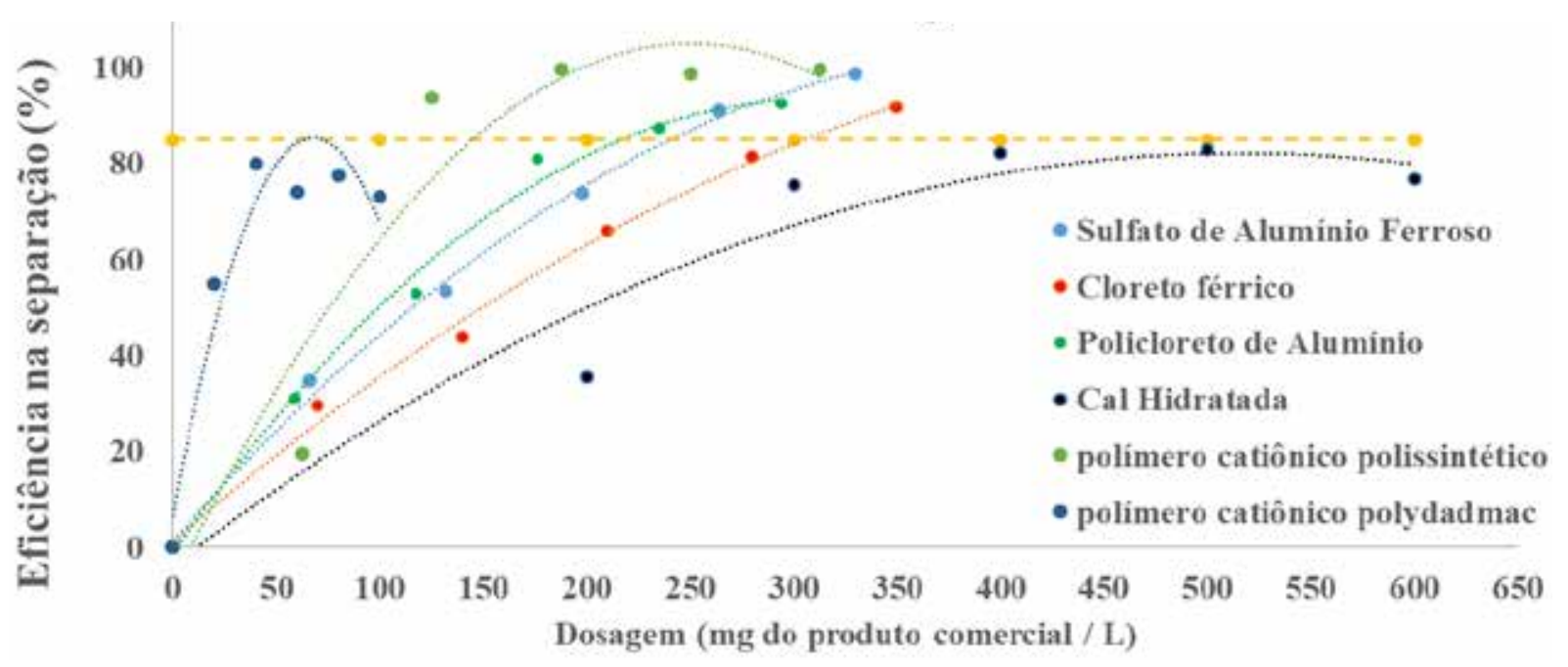

Figura 4. Eficiência dos coagulantes para a colheita de microalgas

Tabela 1. Dados obtidos nos ensaios de Jar Test e análise financeira

\begin{tabular}{|c|c|c|c|c|c|c|}
\hline Coagulante & $\begin{array}{c}\text { pH médio do } \\
\text { meio }\end{array}$ & $\begin{array}{c}\text { Dosagem } \\
\text { utilizada } \mathbf{~ m g / L ~}\end{array}$ & $\begin{array}{c}\text { Eficiência média } \\
\text { na colheita (\%) }\end{array}$ & $\begin{array}{c}\text { pH médio } \\
\text { final do } \\
\text { sobrenadante }\end{array}$ & Preço R\$/Kg & $\begin{array}{c}\text { Custo para } \\
\text { 1000m3 (R\$) }\end{array}$ \\
\hline $\begin{array}{c}\text { Polímero } \\
\text { catiônico } \\
\text { polissintético }\end{array}$ & 8,53 & 0,125 & 93,93 & 7,83 & 4,47 & 558,75 \\
\hline $\begin{array}{c}\text { Sulfato de } \\
\text { alumínio ferroso }\end{array}$ & 8,27 & 0,264 & 91,13 & 6,90 & 0,75 & 198,00 \\
\hline $\begin{array}{c}\text { Policloreto de } \\
\text { alumínio }\end{array}$ & 8,70 & 0,235 & 91,80 & 7,23 & 3,18 & 747,30 \\
\hline $\begin{array}{c}\text { Cloreto Férrico } \\
\text { Polímero }\end{array}$ & 8,70 & 0,350 & 91,80 & 6,17 & 3,09 & $1.081,50$ \\
\hline $\begin{array}{c}\text { catiônico } \\
\text { polydadmac }\end{array}$ & 9,07 & 0,040 & 80,15 & 9,07 & 5,50 & 220,00 \\
\hline Cal hidratada & 8,07 & 0,300 & 75,59 & 11,43 & 0,56 & 168,00 \\
\hline
\end{tabular}

$\mathrm{O}$ pH médio da lagoa teve pequena variação durante as amostragens, com mínimo de 8,07 e máximo de 9,07. Esses valores levemente básicos estão dentro da faixa esperada, devido à atividade fotossíntética e ao consumo de carbono inorgânico nas lagoas (LOPES, 2018). Após a adição dos coagulantes, o pH médio do sobrenadante variou entre 6,17 e 11,43, atingindo o mínimo e o máximo quando foram usados cloreto férrico e cal hidratada, respectivamente. Isso significa que apenas a cal hidratada exigiria uma correção no $\mathrm{pH}$ do sobrenadante antes do descarte, de acordo com a resolução do CONAMA, que especifica um intervalo de $\mathrm{pH}$ entre 5 e 9 para o descarte de efluentes. Os custos dos produtos comerciais foram obtidos diretamente com os fornecedores e também estão dispostos na Tabela 1. 0 custo com coagulantes para o processamento de $1000 \mathrm{~m}^{3}$ de efluente da lagoa, nas condições estudadas, variaram amplamente, desde $\mathrm{R} \$ 168,00$ para a cal hidratada, até $\mathrm{R} \$ 1081,00$ para o cloreto férrico. Coagulantes mais caros não necessariamente resultaram em um maior custo final, uma vez que as dosagens usadas variam significativamente.

$\mathrm{Na}$ Fig. 5, os aspectos das biomassas obtidas, após a etapa secagem e após a etapa de moagem, são apresentados, assim como as cinzas obtidas após os ensaios de poder calorífico. Conforme pode ser observado, o uso de polímeros catiônios conferiu ao lodo um aspecto menos fragmenta- 
do, como se o material estivesse unido por um tipo de "cola". De forma oposta, a biomassa algal obtida sem a presença de coagulantes foi o mais fragmentado. As biomassas produzidas com o uso de de cal hidratada e cloreto férrico, devido à grande quantidade desses materiais, apresentaram coloração esbranquiçada e avermelhada, respectivamente. Já os lodos produzidos com os polímeros catiônicos apresentaram tons esverdeados, semelhantes à coloração da biomassa algal obtida sem a presença de coagulantes. Isso foi atribuído à menor quantidade desses materiais incorporados na biomassa, pela menor dosagem utilizada. Os lodos obtidos com coa- gulantes à base de alumínio apresentaram uma coloração cinza prateada fosca, típica desse metal. A coloração das cinzas também variou, podendo-se notar tons mais coloridos para a presença de metais de transição como o ferro, nas biomassas obtidas com cloreto férrico e sulfato de alumínio ferroso, enquanto tons mais claros e esbranquiçados foram observados para a presença de metais do bloco $s$ e $p$ da tabela períodica, como cálcio e alumínio. Isso está dentro do esperado e, segundo LEE (1999), é causado pela maior facilidade de transição de elétrons para os metais com orbitais $d$ incompletos.

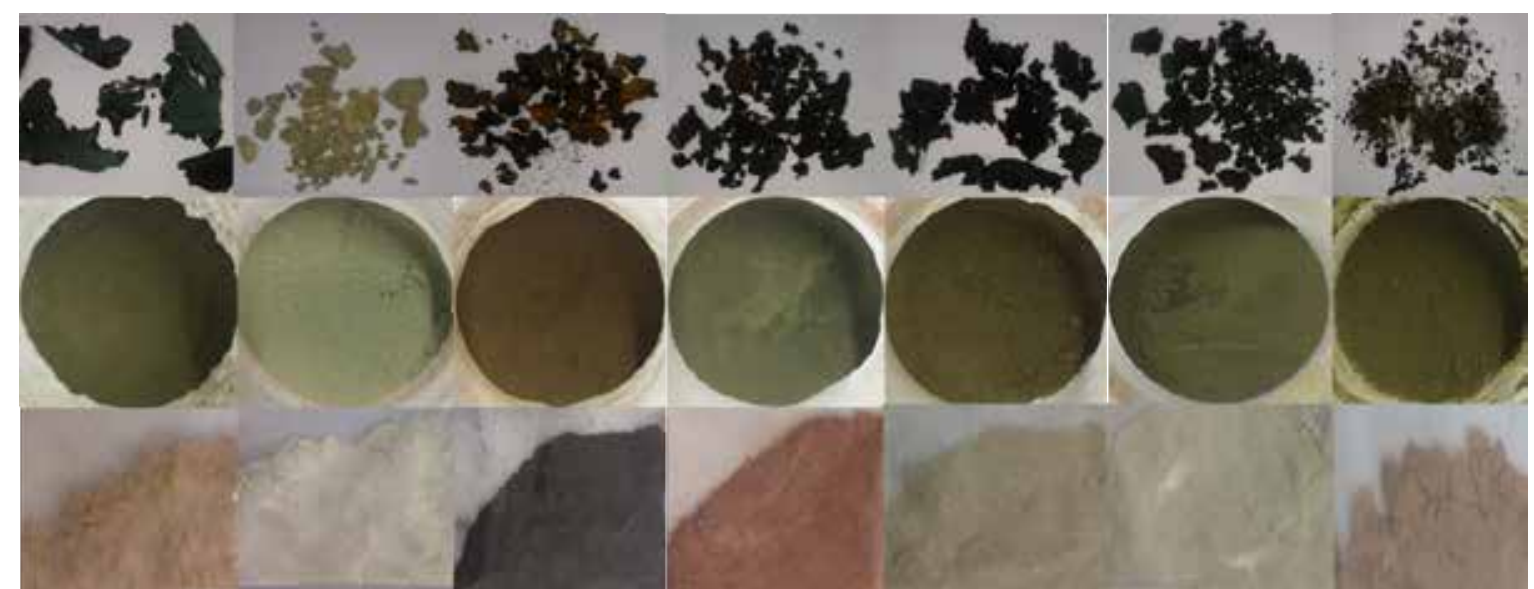

Figura 5. Biomassa algal seca (da esquerda para a direita: polímero catiônico polydadmac; cal hidratada, cloreto férrico, sulfato de alumínio ferroso, polímero catiônico polissintético, policloreto de alumínio, sem coagulante).

A Tabela 2 apresenta o PCS das diferentes biomassas de microalgas avaliadas, assim como de outras fontes de energia, para efeito de comparação. A biomassa algal sem a presença de coagulantes apresentou o maior PCS, 21,58MJ/Kg. Esse valor é compatível com os dados reportados na literatura para as espécies de microalgas mais comuns, reportados na Tabela 3, e é similar ao da madeira, do plástico e do papel, ratificando seu potencial energético. A pequena quantidade do polímero catiônico polydadmac utilizada praticamente não alterou o poder calorífico do lodo e colaborou para um custo final baixo, o terceiro menor. No entanto, todos os outros coagulantes utilizados reduziram de forma significativa o PCS da biomassa final. A biomassa obtida com cal hidratada apresentou um poder calorífico de apenas $3,37 \mathrm{MJ} / \mathrm{Kg}$, o que o torna inviável para a recuperação de energia. A enorme quantidade de cal demandada para elevar o $\mathrm{pH}$ e separar as microalgas causou um excesso de fração inorgânica no lodo e justifica esse número. No entanto, o custo com este material foi o mais barato, e esse tipo de colheita poderia ser usado quando não se 
deseja reaproveitar o lodo para fins energéticos, com reciclagem da cal hidratada. Os demais coagulantes reduziram o PCS mas não o suficiente para inviabilizar a recuperação energética, uma vez que os valores estão no mesmo intervalo da madeira. O cloreto férrico gerou uma biomassa algal de PCS intermediário, quando comparado aos demais. No entanto, o alto custo observado, o maior entre todos os avaliados, desmotiva sua aplicação. $O$ lodo obtido com policloreto de alumínio apresentou o segundo menor PCS e o segundo maior custo, o que significa um balanço final desfavorável para sua utilização. As biomassas obtidas com polímero catiônico po- lissintético e com sulfato de alumínio ferroso apresentaram valores intermediários, tanto para o PCS como para os custos envolvidos, e poderiam ser melhor avaliados, junto com o polímero catiônico polydadmac, que teve o melhor resultado. Recomenda-se um estudo mais aprofundado para esses coagulantes, com ensaios de Jar Test para diferentes condições de $\mathrm{pH}$ e com avaliações de cenários econômicos diferentes. É possível que seja vantajoso investir em alcalinizantes e/ou acidificantes e em etapas adicionais para ajustar o $\mathrm{pH}$ no processo, visando reduzir a quantidade de coagulante e seus impactos no custo e no poder calorífico.

Tabela 2. Poder calorífico superior da biomassa algal e de outros resíduos

\begin{tabular}{|c|c|c|}
\hline Amostra & PCS Médio (MJ/Kg) & Desvio Padrão / Referência \\
\hline Biomassa algal sem coagulante & 21,58 & 0,036 \\
\hline Biomassa algal com polímero catiônico polydadmac & 21,19 & 0,045 \\
\hline Biomassa algal com polímero catiônico polissintético & 16,18 & 0,074 \\
\hline Biomassa algal com cloreto férrico & 14,45 & 0,013 \\
\hline Biomassa algal com sulfato de alumínio ferroso & 12,91 & 0,061 \\
\hline Biomassa algal com policloreto de alumínio & 12,19 & 0,091 \\
\hline Biomassa algal com cal hidratada & 3,37 & 0,034 \\
\hline Carvão & $27-31$ & MOLINO et al., 2017 \\
\hline Madeira & $12-19$ & MOLINO et al., 2017 \\
\hline Plástico e papel & $17,6-20$ & MANARA e ZABANIOTOU, 2012 \\
\hline
\end{tabular}

Tabela 3. Poder calorífico superior (PCS) relatado para microalgas na literatura

\begin{tabular}{|c|c|c|}
\hline \multicolumn{1}{|c|}{ Referência } & Espécie/ Biomassa algal & PCS (MJ/kg) \\
\hline CAPUTO et al., 2016 & Acutodesmus obliquus & 23,30 \\
\hline ONWUDILI et al., 2013 & Chlorella vulgaris & 23,20 \\
\hline RAHEEM et al., 2015 & Chlorella vulgaris & 22,50 \\
\hline ONWUDILI et al., 2013 & Spirulina platensis & 21,20 \\
\hline MILLER et al., 2012 & Nannochloropsis gaditana & 21,12 \\
\hline ELLIOTT et al., 2012 & Chlorella vulgaris & 21,10 \\
\hline BROWN et al. 2010 & Nannochloropsis sp. & 19,00 \\
\hline LANE, D.J. et al., 2014 & Tetraselmis sp. & 15,50 \\
\hline ZHU, Y. et al. 2016 & Scenedesmus sp. & 15,40 \\
\hline
\end{tabular}




\section{CONCLUSÕES}

Este trabalho quantificou o PCS da biomassa de microalgas, cultivada em lagoas de alta taxa com efluente de reator UASB, tratando esgoto doméstico. Pôde-se observar que os coagulantes utilizados na etapa de colheita interferem largamente no PCS da biomassa algal produzida. Dentre os coagulantes testados, os mais vantajosos do ponto de vista energético e financeiro, foram o polímero catiônico polydadmac, o polímero catiônico polissintético e o sulfato de alumínio ferroso. Todos esses compostos reduziram o PCS da biomassa algal, embora os valores observados ainda sejam similares aos da madeira, o que sugere uma possível viabilidade em processos termoquímicos para geração de energia. Na faixa de pH natural da lagoa avaliada, entre 8,07 e 9,07, o coagulante polímero catiônico polydadmac teve o melhor custo-benefício, e o PCS da biomassa algal obtida foi de $21,19 \mathrm{MJ} / \mathrm{Kg}$.

\section{AGRADECIMENTOS}

Os autores agradecem o apoio financeiro fornecido por CNPq, FAPES, Finep (número: 01.06.0593.00 - CHAMADA PÚBLICA MCT/FINEP - AÇÃO TRANSVERSAL, BRASIL). Os autores também agradecem à CESAN e ao NEST.

\section{CONTRIBUIÇÃO DOS AUTORES}

Todos os autores contribuíram de forma igualitária.

\section{REFERÊNCIAS}

ANTHONY, R. J. et al. Effect of coagulant/flocculants on bioproducts from microalgae. Bioresource Technology, v. 149, p. 65-70, 2013.

BROWN, T. M. et al. Hydrothermal liquefaction and gasification of Nannochloropsis sp. Energy and Fuels, v. 24, n. 6, p. 3639-3646, 2010.

CAPUTO, G. et al. Supercritical water gasification of microalgae and their constituents in a continuous reactor. Journal of Supercritical Fluids, v. 118, 2016.
CASTRILLO, M. et al. High pH-induced flocculation-sedimentation and effect of supernatant reuse on growth rate and lipid productivity of Scenedesmus obliquus and Chlorella vulgaris. Bioresource Technology, v. 128, p. 324-329, 2013.

CONAMA. Resolução № 430, de 13 de maio de 2011. Publicada no DOU nº 92, de 16/05/2011, pág. 89.

DAS, P. et al. Microalgae harvesting by $\mathrm{pH}$ adjusted coagulation-flocculation, recycling of the coagulant and the growth media. Bioresource Technology, v. 216, p. 824-829, 2016.

DUMAN, G. et al. Hydrogen production from algal biomass via steam gasification. Bioresource Technology, v. 166, 2014.

ELLIOTT, D. C. et al. Chemical processing in high-pressure aqueous environments. 9. Process development for catalytic gasification of algae feedstocks. Industrial and Engineering Chemistry Research, v. 51, n. 33, p. 10768-10777, 2012.

FERRARI, F. G. Pós-tratamento do efluente de lagoa facultativa primária através da utilização de coagulantes metálicos e polímeros. Dissertação (Mestrado em Engenharia Ambiental) Universidade Federal do Espírito Santo. Vitória, 2018

GERCHMAN, Y. et al. Effective harvesting of microalgae: Comparison of different polymeric flocculants. Bioresource Technology, v. 228, p. 141-146, 2017.

HEIDENREICH, S.; FOSCOLO, P. U. New concepts in biomass gasification. Progress in Energy and Combustion Science, v. 46, p. 72-95, 2015.

JANKOWSKA, E. et al. Biogas from microalgae: Review on microalgae's cultivation, harvesting and pretreatment for anaerobic digestion. Renewable and Sustainable Energy Reviews, v. 75, n. October 2015, p. 692-709, 2017.

LAM, M.K.; LEE, K.T. Cultivation of Chlorella vulgaris in a pilot-scale sequential-baffled column photobioreactor for biomass and biodiesel production. Energy Conversion and Management, v. 88, 2014.

LANE, D.J. et al. Combustion behavior of algal biomass: Carbon release, nitrogen release, and char reactivity. Energy and Fuels, v. 28, n. 1, 2014.

LEE, J.D. Química inorgânica não tão concisa. Tradução da $5^{\mathrm{a}} \mathrm{ed}$. Inglesa, São Paulo, Editora Edgard Bluche, 1999.

LOPES, N. T. Influência do tempo de detenção hidráulica e da profundidade no desempenho de lagoas de alta taxa aplicadas ao pós-tratamento de efluente de reatores UASB. Dissertação (Mestrado em Engenharia e Desenvolvimento Sustentável), Universidade Federal do Espírito Santo. Vitória, 2018.

LÓPEZ-GONZÁLEZ, D. et al. Comparison of the steam gasification performance of three species of microalgae by thermogravimetric-mass spectrometric analysis. Fuel, v. 134, 2014. 
MANARA, P.; ZABANIOTOU, A. Towards sewage sludge based biofuels via thermochemical conversion - A review. Renewable and Sustainable Energy Reviews, v. 16, n. 5, p. 2566-2582, 2012.

MILLER, A. et al. Exploration of the gasification of Spirulina algae in supercritical water. Bioresource Technology, v. 119, p. $41-47,2012$

MINOWA, T; SAWAYAMA, S. A novel microalgal system for energy production with nitrogen cycling. Fuel, v. 78, n. 10, p. 12131215, 1999.

MOLINO, A. et al. Supercritical water gasification of scenedesmus dimorphus $\mu$-algae. International Journal of Chemical Reactor Engineering, v. 15, n. 4, 2017.

ONWUDILI, J.A. et al. Catalytic hydrothermal gasification of algae for hydrogen production: Composition of reaction products and potential for nutrient recycling. Bioresource Technology, v. $127,2013$.

PATEL, B. et al. A review on hydrothermal pre-treatment technologies and environmental profiles of algal biomass processing. Bioresource Technology, v. 199, 2016.
PENG, G. et al. Catalytic Supercritical Water Gasification: Continuous Methanization of Chlorella vulgaris. Industrial and Engineering Chemistry Research, v. 56, n. 21, 2017.

RAHEEM, A. et al. Thermochemical conversion of microalgal biomass for biofuel production. Renewable and Sustainable Energy Reviews, v. 49, 2015.

SOREANU, G. et al. CO2 gasification process performance for energetic valorization of microalgae. Energy, v. 119, 2017.

VANDAMME, D. et al. Flocculation as a low-cost method for harvesting microalgae for bulk biomass production. Trends in Biotechnology, v. 31, n. 4, p. 233-239, 2013.

WAN, C. et al. Current progress and future prospect of microalgal biomass harvest using various flocculation technologies. Bioresource Technology, v. 184, p. 251-257, 2015.

ZHU, Y. et al. Fluidized Bed Co-gasification of Algae and Wood Pellets: Gas Yields and Bed Agglomeration Analysis. Energy and Fuels, v. 30, n. 3, 2016. 